\title{
Strategies for Demand-side Management in an Office Building Integrated with Rooftop Façade PV Installations
}

\author{
Davide Papurello ${ }^{1,2}$, Vitangelo Vitulli ${ }^{1,2}$, Francesco Minuto ${ }^{1,2}$, Lorenzo Bottaccioli ${ }^{1,3}$, Andrea Lanzini ${ }^{1,2^{*}}$, Romano \\ Borchiellini ${ }^{1,2}$ \\ ${ }^{1}$ Energy Center Lab, Via Paolo Borsellino 38/16, Energy Center - Politecnico di Torino, Torino 10129, Italy \\ ${ }^{2}$ Department of Energy - Politecnico di Torino, Corso Duca degli Abruzzi 24, Torino 10129, Italy \\ ${ }^{3}$ Department of Control and Computer Engineering - Politecnico di Torino, Corso Duca degli Abruzzi 24, Torino 10129, Italy
}

Corresponding Author Email: andrea.lanzini@polito.it

https://doi.org/10.18280/ti-ijes.632-428

Received: 25 February 2019

Accepted: 27 April 2019

\section{Keywords:}

demand side management, energy management, building automation, energy metering

\begin{abstract}
Strategies for demand side management in an office building located in the North-West of Italy with $47 \mathrm{kWp}$ of rooftop and façade PV installations are identified and quantified in terms of energy shifting.

The building energy management system provides data on environmental variables (e.g., the set-point and measured temperature of each room) and energy vectors (i.e., electricity and heat) that are exchanged by the building with the available energy grids (i.e., a lowvoltage electricity distribution grid and a district heating network).

The thermal and electric loads of the building have been monitored for more than a year to identify opportunities for demand-side management.

By monitoring the temporal evolution of the temperature profile (decay) of the building at night, when no solar heat gain is present and no additional heat gains are virtually in place (all the heat distribution systems and mechanical ventilation are at rest), we estimated the amount of load shifting that could be applied during office hours without creating significant temperature overshot that could trigger thermal discomfort of the occupants.
\end{abstract}

\section{INTRODUCTION}

The increasing awareness about climate change issues has considerably increased the international community attention towards Renewable Energy Sources (RES). Related to RES penetration in the actual electricity grids makes rise issues related to grid security. On the supply side, in fact this can lead to difficulties in balancing supply and demand, while the decarbonization of transport and space conditioning may induce to both increasing the electricity load and the electricity peak demand [1].

Demand-Side Management (DSM) for buildings represents a cost-effective way that, reversing the actual energy paradigm mainly focused on supply, may help in pursuing a more sustainable energy sector in all its aspects: equity, security and environmental sustainability [2-4]. As a matter of fact, DSM contribution may help in ensuring the electricity balance when system reliability is jeopardized, increasing security and consequently allow a higher penetration of RES. Moreover, considering the direct involvement of demand-side, it allows the consumer to participate to the energy market, increasing even energy equity.

This work represents a preliminary approach in investigating opportunities related to Demand-Side Management practices in an office building, the Energy Center of the Polytechnic University of Turin. Through direct observation of energy consumption and internal temperature profiles, it has been proposed as a DSM strategy: the load curtailing peak. Estimated results show that, without compromising the thermal comfort, two load curtailing strategies analysed for cooling and pre-cooling strategies, presents respectively a potential energy saving of $10 \%$ and $35 \%$ on daily consumption.

\section{CASE STUDY}

The Energy Center (EC) building was considered as case study. It is composed by three floors with exposition area $(925$ $\mathrm{m}^{2}$ ) and offices $\left(3000 \mathrm{~m}^{2}\right)$, by a laboratory in the basement $\left(327 \mathrm{~m}^{2}\right)$, by a laboratory closed to the main entrance $\left(450 \mathrm{~m}^{2}\right)$ and by an auditorium with 150 seats $\left(150 \mathrm{~m}^{2}\right)$.

The building has a $47 \mathrm{kWp}$ photovoltaic plant installed in the façade $(13 \mathrm{~kW})$, roof stair A $(13 \mathrm{~kW})$, roof stair B $(13 \mathrm{~kW})$ and coverage $(8 \mathrm{~kW})$. A multi-purpose geothermal group, or polyvalent group is installed with a power of $473 \mathrm{~kW}$ (heating), $442 \mathrm{~kW}$ (cooling) and DHW production. Moreover, the building is connected to the district heating network through three sub-station heat exchangers for heating, DHW production and feeding of a $\mathrm{LiBr}$ absorption chiller $(155 \mathrm{~kW})$ for cooling purposes. It achieves high quality of indoor comfort using also mixed technologies, such as air/water HVAC system, with radiant panels (floors and ceiling) and primary air supply.

The rules chosen for the energy management in the Center, during its first year of activity (2018), are reported below:

(1). Heating season from October 15th to April 15th,

(2). Scheduling of the plants in the heating season from 7:00 AM to 7:00 PM

(3). Heating using mainly the district heating network 
(DHN)

(4). Domestic hot water supplied by polyvalent group or

DHN

(5). Cooling mainly supplied by polyvalent group

(6). Photovoltaic electrical production, totally selfconsumed

(7). Thermal solar production, totally self-consumed

The control system installed in the Center exploits smart meters and Direct Digital Control (DDC) units (Siemens desigo $\mathrm{cc}^{\mathrm{TM}}$, Milan, Italy) that are distributed in the building.

In this work we intended to evaluate the opportunities of DSM by a direct observation of the building thermal behaviour applying a load curtailing strategy managing on the Polyvalent Group during the cooling season. By monitoring the temporal evolution of the temperature profile (decay) of the building at night, when no solar heat gain is present and no additional heat gains are virtually in place (all the heat distribution systems and mechanical ventilation are at rest), it was estimated the amount of load shifting that could be applied during office hours without creating significant temperature overshot that could trigger thermal discomfort of the occupants.

This approach makes possible to consider the effects of internal temperature gradients, internal resistance of the body (conduction) and external resistance (convection).

\section{RESULTS}

\subsection{Building thermal response estimation}

In order to have a rough understanding of the building behaviour in terms of its thermal mass, it has been evaluated a sort of thermal time response using the measured temperature at disposal. For this first assessment, the building has been considered as a single black box, therefore the following considerations have been done observing the average of the internal temperature measured. This assessment has been performed in order to have a first rough measure of building capability to provide flexibility exploiting its good characteristics in terms of thermal mass, having an estimation of the possible consequent discomfort. As a matter of fact, the aim of this evaluation is to provide an experimental reference value of decay (winter) or increase (summer) of temperature consequently to the possible shutdown of the Heating and/or Cooling systems.

Firstly, it has been considered a week of December 2018 as sample. Therefore, it has been observed the temperature decay from the shutdown of the plants in the evening (19:00), to the following morning (7: 00). It has been evaluated a mean temperature decay of $0.2{ }^{\circ} \mathrm{C} / \mathrm{h}$, which represents a conservative estimation because of the worst conditions presented by the time-frame observed:

-Heating plant off;

-Absence of Solar Irradiance. Considering that flexibility strategies are usually applied during the day, for sunny days the temperature decays will surely be lower.

-Unoccupancy. Heat gains related to occupants and their activities led to a reduction in heating load.

It should be necessary to consider another factor that increase the heating load: ventilation.

Doing the same evaluation for the Cooling season is slightly more trivial. The worst situation available is the Sunday morning with an average internal temperature increase of approximately $0.2{ }^{\circ} \mathrm{C} / \mathrm{h}$. Anyway, with respect to the heating season, this value is not conservative because evaluated for the following conditions:

-Cooling plant off;

-Presence of Solar Irradiance;

-Unoccupancy.

While for the previous case "Unoccupancy" represented a conservative situation, for summer season it is the contrary because "Occupancy", and all the internal gains related to the users activities, represent an additional cooling load. Therefore, it was obtained a value doubled with respect to the one calculated on Sunday morning. The temperature increase estimated was equal to $0.4^{\circ} \mathrm{C} / \mathrm{h}$ to avoid an overestimation of flexibility potential.

\subsection{Pre-cooling peak shaving strategy}

The peak power showed in the cooling periods is completely caused by the polyvalent group. Therefore, in order to reduce that peak, it could be possible to evaluate the implementation of a pre-cooling strategy. Considering the actual thermoregulation of the Polyvalent group as function of the load it could be possible to implement the strategy in two different ways:

(1). Acting on the supplied water temperature setpoint, and so acting on the temperature difference. In this case, the strategy provides the system turning on in advance with a gradual increase of the supply water temperature setpoint starting from a lower value with respect to the normal operation;

(2). Acting on the flowrate. Even in this case, the strategy provides the system turning on in advance with a gradual increase of the requested cold-water flowrate.

Considering the second way exposed, it could be possible to act on the different loads served by the Polyvalent Group during the cooling season, whose nominal powers has been reported in Table 1 .

The fluid distribution system of the building, considering both pumps and valves, allows to have a good control on the load in terms of flowrate requested. It could be possible both to act on the pumps of the different load utilities, controlling their operating speed and so managed flowrate, or on the load utilities valves. For the second case, the systems present a very good granularity that would allow a fine regulation of the load. For this first assessment, Figure 1 shows the expected results of the application of a supposed strategy with an observed reduction in load peak of $35 \%$.

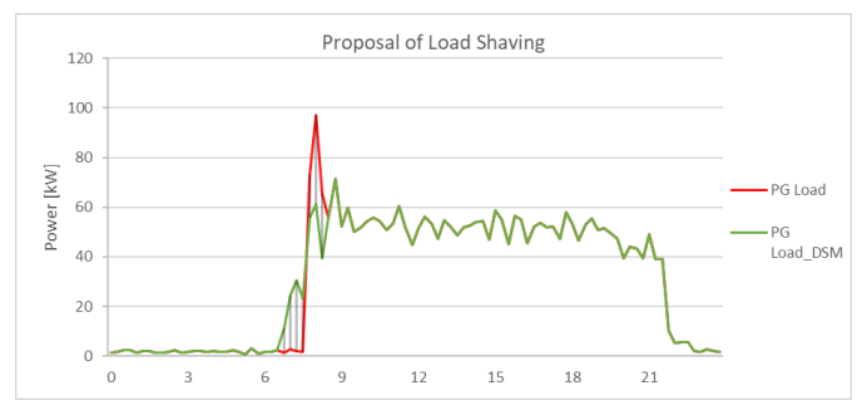

Figure 1. Possible effects of a Pre-cooling strategy applied to Polyvalent Group

It is necessary to notice that to evaluate the real consequences to the load it is necessary to perform simulations or implementation tests. In this initial speculation, a simple energy balance has been applied, evaluating the contribution 
of each load with a simple proportion with respect the nominal load showed in Table 1. Considering the occasional unoccupancy of Auditorium and Basement, the AHU of such areas has been excluded for this first analysis.

Table 1. Main cooling loads nominal power

\begin{tabular}{c|ccc}
\hline & & Offices & $106 \mathrm{~kW}(41 \%)$ \\
& & NW & $10.6 \mathrm{~kW}$ \\
& & Offices NE & $(10.6 \%)$ \\
AHU & $259 \mathrm{~kW}$ & & $37.8 \mathrm{~kW}$ \\
& $(56.8 \%)$ & Hall & $(14.6 \%)$ \\
& & Basement & $39.5 \mathrm{~kW}$ \\
& & & $(15.2 \%)$ \\
& & Auditorium & $48.2 \mathrm{~kW}$ \\
Radiant & & & $(18.6 \%)$ \\
Floors & $(4.5 \%)$ & $/$ & $/$ \\
& & Floor 1 & $51.2 \mathrm{~kW}$ \\
Radiant & $160 \mathrm{~kW}$ & Floor 2 & $51.2 \mathrm{~kW}$ \\
Ceilings & $(35 \%)$ & & $(32 \%)$ \\
& & Floor 3 & $57.6 \mathrm{~kW}$ \\
& & & $(36 \%)$ \\
Storage & $17 \mathrm{~kW}$ & $/$ & $/$ \\
\hline
\end{tabular}

Therefore, it is supposed to shift the different loads in time, anticipating the turning on of the Polyvalent Group but increase in different step the cool water flowrate requested, adding at different time the utilities load, supposing to open the respective valve at different times as follow:

(1). 6:30 - Third floor radiant ceiling valves;

(2). 6:45 - Second floor radiant ceiling valves;

(3). 7:00 - First floor radiant ceiling valves;

(4). 7:15 - Radiant floor valves (Hall);

(5). 7:30 - AHU batteries.

Obviously, the order showed is just a proposal that could be perfectionated considering the level of comfort and discomfort of the various floors. For example, Hall and Third floor areas may present a higher cooling load due to their higher exposition. Therefore, could be suggestable to start from these two areas. In terms of applicability, as already discussed previously, the HVAC systems are controlled with a single clock. In order to apply such strategy, it should be necessary to separate the systems to different clocks. Higher is the number of clocks for the different systems, higher is the granularity of control and so lower is the rate of increase of the power. But it is suggestable to find a trade-off between the granularity of control and simplicity of systems management to avoid high complexity in setting up the desired programs.

\subsection{Electricity load curtailing}

In order to evaluate the capability of the building to participate to Demand Response programs, it has been tried to estimate the potential of Polyvalent Group (PG) curtailing, which represents the higher contribution to the electricity consumption during cooling season, speculating on the possible effects on the thermal comfort exploiting the reference temperature increase calculated. It has been assumed a flexible availability period of $120 \mathrm{~min}$.

Figure 2 shows the possible effects of the implementation of such strategy. After the beginning of the flexibility event, the reference rate of temperature increase has been applied. It has been chosen to apply the flexibility event from 11:30 to 13:30 because it can be assumed that from 12.30 to approximately 14 , occupants may be out of the building for the lunch. As it is possible to observe, the temperature path presents a delay with respect to the load which is related to the thermal mass effect of the building. Therefore, the observed delay of approximately 30 minutes has been kept even for the subsequent observations on the modified path. Then after the restoration to normal operation, a possible rebound peak has been estimated necessary to bring back the temperature to the normal operation (intended as the original path). For this first assessment, the rebound has been evaluated applying a simple energy balance, rescaling the energy necessary to decrease the internal temperature from 7:00 to 9:00 with respect to the temperature difference necessary to restore normal operation. Considering a temperature limit to avoid discomfort of $26^{\circ} \mathrm{C}$ it is possible to affirm that this strategy would potentially not affect occupants thermal comfort, with a resulted estimated saving in electricity consumption of the day analysed of approximately $10 \%$.

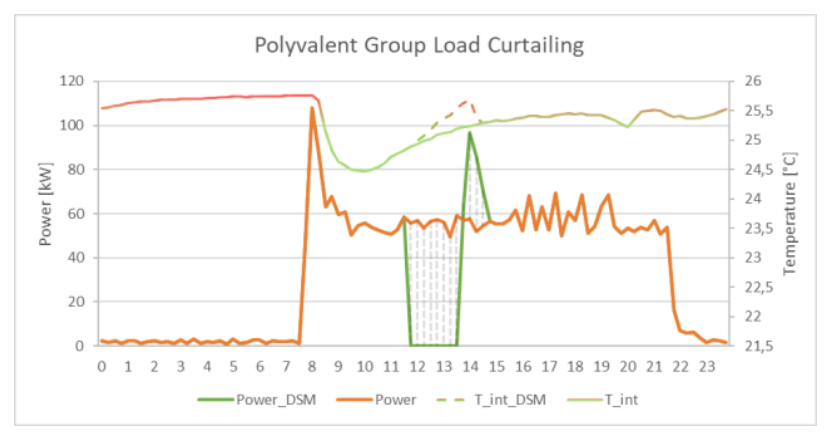

Figure 2. Possible load curtailing effects on a sample day electricity consumption and internal temperatures profiles

In terms of controllability and so implementation, the supervision system allows to directly control the Polyvalent Group load shutting down the machine, managing the supply temperature setpoint or it could be even possible to turning off the distribution system unloading the machine. It is suggestable to program such tests in different Weekdays of the summer periods to take into account the variability of the cooling load of the building.

In terms of observability, it is necessary to perfectionate the monitoring system in order to control all the comfort parameters that could be affected by the strategy implementation. Therefore, it is necessary to historicize and to observe the temperature evolution of the different areas of the building. Particular attention should be paid for area exposed to high irradiation levels that could reach discomfort conditions sooner.

It is suggestable to couple the monitoring of the temperature evolution with occupants questionnaire in order to take into account even the subjective nature of the thermal comfort perception. In order to avoid occupants high dissatisfaction, it is suggestable to advise them of the intention to perform tests but to avoid communicating the occupants the exact days and hours of the test, in order to keep the interview results as more objective as possible.

Therefore, in the following will be summarized the suggested steps for the execution of the implementation tests of this strategy:

(1). Improvement of monitoring system: ensure the monitoring of zone temperature evolution; 
(2). Information of occupants about the future execution of tests;

(3). Prepare and provide to occupants a questionnaire for comfort assessment (EN 15251 suggestions could be used as starting point).

(4). Select a set of days in which request the compilation of the questionnaire, during which apply or not the strategy.

(5). Collect measurements of electricity consumption and comfort parameters monitoring and try to compare days as much similar as possible.

In general, it is suggestable to have even the measurements of the Polyvalent Group heat meters, in order to have a deeper understanding of machine behaviour. These aspects are under evaluation with real time sensors data.

\section{CONCLUSIONS}

For this first approach to DSM in Energy Center it has been analysed two of the phases described in the suggested framework, information gathering and potential estimation, essential for the preparation of the essential knowledge of building systems towards future implementation of DSM practices. In first, an information collection step has been performed, which have involved different actors of building energy management organization. It has been founded several inconsistencies in design information which have requested a time consuming coupled with technical staff interviews and inspections. This step has highlighted the high potential of BACS system of the building but, at the same time, necessary improvement about the monitoring system. Then, exploiting the typical day profile or, due to unavailability of measurements, some sample days, some Demand-side Management interventions has been evaluated in terms of estimation of the related potential implementation and are summarized in the following:

(1). Proposal of a pre-cooling peak shaving strategy. It has been estimated a reduction in peak load of $35 \%$ anticipating the turning on of the systems by half an hour and adding gradually the different loads.

(2). Evaluation of a load curtailing strategy of the polyvalent group. Considering a 2 hours curtailment and estimating a rebound energy to bring back the internal conditions to normal operation it has been estimated an energy saving of approximately $10 \%$ in the day analysed without overcoming an internal temperature limit of $26^{\circ} \mathrm{C}$.

\section{REFERENCES}

[1] Council of European Energy Regulators. (2016). Flexibility Task Force Principles for valuation of flexibility Position Paper.

[2] Nadeau M. (2016). World Energy Scenarios 12016.

[3] C. of E.E.R. Asbl. (2016). Principles for valuation of flexibility: Position Paper.

[4] Lizana J, Friedrich D, Renaldi R, Chacartegui R. (2018). Energy flexible building through smart demand-side management and latent heat storage. Appl. Energy 230: 471-485. https://doi.org/10.1016/j.apenergy.2018.08.065

\section{NOMENCLATURE}

AHU, Air Handling Unit; BACS, Building Automation and Control System; DDC, Direct Digital Control;

DHN, District Heating Network;

DHW, Domestic Hot Water;

DSM, Demand Side Management;

HVAC, Heating, Ventilation and Air Conditioning;

PG, Polyvalent Group;

PV, Photovoltaic panel;

RES, Renewable Energy Sources. 